\title{
Anti-inflammatory effects of kudingcha methanol extract (Ilex kudingcha C.J. Tseng) in dextran sulfate sodium-induced ulcerative colitis
}

\author{
JIA-LE SONG ${ }^{1 *}$, YU QIAN ${ }^{2 *}$, GUI-JIE LI $^{2}$ and XIN ZHAO ${ }^{2}$ \\ ${ }^{1}$ Department of Food Science and Nutrition, Pusan National University, Busan 609-735, Republic of Korea; \\ ${ }^{2}$ Department of Biological and Chemical Engineering, Chongqing University of Education, Chongqing 400067, P.R. China
}

Received April 3, 2013; Accepted August 8, 2013

DOI: $10.3892 / \mathrm{mmr} .2013 .1635$

\begin{abstract}
The present study aimed to investigate the anti-inflammatory effects of Ilexkudingcha C.J.Tseng methanol extracts (KME) on $3 \%$ dextran sulfate sodium (DSS)-induced ulcerative colitis (UC) in mice (C57BL/6J strain). Body weight, disease activity index (DAI), colon length, colon weight to length ratio, colonic myeloperoxidase (MPO), glutathione (GSH) and malondialdehyde (MDA) levels were measured. Histological changes were observed by hematoxylin and eosin staining. Colonic levels of tumor necrosis factor- $\alpha$ (TNF- $\alpha$ ), interleukin(IL)-1 $\beta$ and IL-6 were measured with an enzyme-linked immunosorbent assay. The mRNA expression of TNF- $\alpha$, IL-1 $\beta,-6$, inducible nitric oxide synthase (iNOS) and cyclooxygenase-2 (COX-2) in the colon tissue, was quantified by RT-PCR. KME significantly suppressed DSS-induced body weight loss, colon length shortening and decreased the colon weight to length ratio. It also resulted in increased GSH and reduced MPO and MDA levels in the colon tissue. Histological observation suggested that KME prevented edema, mucosal damage and loss of crypts, which are induced by DSS. In addition, KME decreased the levels of TNF- $\alpha$, IL-1 $\beta$ and -6 in the colon tissues, while inhibiting the mRNA expression of these cytokines, as well as iNOS and COX-2. The results of this study suggested that KME has anti-inflammatory effects on DSS-induced UC in mice (C57BL/6J strain) by reducing the colonic levels and inhibiting the mRNA expression of pro-inflammatory cytokines.
\end{abstract}

Correspondence to: Dr Xin Zhao, Department of Biological and Chemical Engineering, Chongqing University of Education, 9 Xuefu Main Street, Nan'an District, Chongqing 400067, P.R. China

E-mail: foods@live.cn

*Contributed equally

Key words: Ilex kudingcha C.J. Tseng, anti-inflammation, dextran sulfate sodium, colitis

\section{Introduction}

Human inflammatory bowel disease (IBD), a type of serious gastrointestinal tract disease that includes ulcerative colitis (UC) and Crohn's disease (CD), is characterized by recurrent chronic inflammation and mucosal tissue damage of the gastrointestinal tract (1). However, the etiology of IBD remains unknown. Generally, IBDs are the result of various factors including environmental, genetic and lifestyle effects, as well as immunological disorders $(1,2)$. In particular, immunological disorders have resulted in an imbalance between pro-inflammatory cytokines, such as tumor necrosis factor- $\alpha$ (TNF- $\alpha$ ), interferon- $\gamma($ IFN- $\gamma)$, interleukin (IL)-1 $\beta$, -6 and -12 , and anti-inflammatory cytokines such as IL-4 and -10. Therefore, cytokines may be important in the pathological process of IBD (3). The inflammatory response begins with an infiltration of neutrophils and macrophages. Activated macrophages produce a potent mixture of broadly active inflammatory cytokines, such as TNF- $\alpha$, IL- $1 \beta$ and -6 which subsequently causes damage to the colonic tissues $(4,5)$. Downregulation of the aberrant immune response and inhibition of the pro-inflammatory cytokines that induce inflammatory cascades, has been recognized as a major therapeutic target in IBD treatment (6).

Traditional therapeutic agents, including 5-aminosalicylaes (5-ASA) and corticosteroids, which are used in clinical IBD treatment, are also associated with serious complications and undesirable side effects (7). 5-ASA is well tolerated but diarrhea, cramps and abdominal pain are occasional side effects and these may be accompanied by fever, rash or kidney problems. Corticosteroids also result in systemic immunosuppression and have several well-known side effects, such as rounding of the face, acne, increased body hair, diabetes, weight gain and high blood pressure (8). For these reasons, the development of effective and safe therapeutic agents to treat IBD, has become increasingly important.

Kudingcha is a bitter tea that is prepared from Ilexkudingcha C.J. Tseng. It has been consumed traditionally as a herbal tea in China, Vietnam and various regions of Southwest Asia (9). Kudingcha has been demonstrated to exhibit numerous beneficial functions, including antioxidant, -obesity, -diabetic, -inflammatory, cardiovascular, hepatoprotective and neuroprotective activities (10-18). Previous studies have identified 
that kudingcha is rich in polyphenolic compounds, such as caffeoylquinic acid (CQA) and its derivatives $(11,12,19)$. In the present study, we investigated the anti-inflammatory effects of Ilex kudingcha C.J. Tseng methanol extract using an in vivo animal model of IBD, induced by DSS.

\section{Materials and methods}

Chemicals andreagents. DSS (molecularweight: 36,00-50,000) was obtained from MP Biomedicals (Solon, OH, USA). TRIzol reagent, OligodT $T_{18}$ primer, murine maloney leukemia virus (MMLV) reverse transcriptase, RNase inhibitor, ethidium bromide $(\mathrm{EtBr})$ and agarose, were purchased from Invitrogen Life Technologies (Carlsbad, CA, USA). All other reagents were of analytical grade.

Plant extract preparation. Fresh kudingcha (Ilex kudingcha C.J. Tseng.) leaves were purchased from a local market in Chongqing, China in October, 2012. The fresh kudingcha leaves were freeze-dried and then ground into a fine powder. A 12-fold volume of methanol $(80 \%, \mathrm{vol} / \mathrm{vol})$ was added to the powdered samples and extracted three times by stirring overnight. Kudingcha methanol extracts (KME) were concentrated by heat evaporation, cryodessication and stored at $4^{\circ} \mathrm{C}$ until further study.

Animal studies. Male mice (C57BL/6J strain; age, 6 weeks) were purchased from the Experimental Animal Center of Chongqing Medical University (Chongqing, China). The mice were housed in a standard 12-h light/dark cycle at room temperature, and had ad libitum access to food and water. Colitis was induced in mice by administration of $3 \%$ (wt/vol) DSS in the drinking water for 7 days. Mice were randomly divided into four groups with 6 mice per group: Group 1, the normal controls were treated with $0.9 \%$ normal saline; group 2 , DSS-treated mice and groups 3 and 4 received DSS and were administered with $\mathrm{KME}$ (50 and $200 \mathrm{mg} / \mathrm{kg}$ ) daily via an intragastric route $(0.2 \mathrm{ml} / \mathrm{mouse})$ for 7 days, until sacrifice. The animal protocol used in this study was reviewed by the Animal Ethics Committee of Chongqing Medical University.

Evaluation of disease activity index (DAI). The DAI was used to evaluate the grade and extent of intestinal inflammation. Body weight, stool consistency and blood in the stools were monitored daily for determination of DAI. Each score was provided as follows: Body weight loss (0, none; 1, 1-5\%; $2,5-10 \% ; 3,10-20 \% ; 4,>20 \%$ ), diarrhea ( 0 , normal; 2 , loose stools; 4, watery diarrhea) and blood (0, normal; 2, slight bleeding; 4, gross bleeding). The DAI score ranged from 0 to 12 (total score) (20). The mice were sacrificed on day 7, and the weight and length of the colon were measured.

Histological observations. The distal colons from each animal were subjected to histological examination. The colon tissues were fixed in $10 \%$ (vol/vol) neutral-buffered formalin, dehydrated in ethanol and embedded in paraffin. Colon tissue sections $(4 \mu \mathrm{m})$ were then cut and stained with hematoxylin and eosin (H\&E).

Myeloperoxidase (MPO) activity. MPO activity was assessed as described previously (21), but with modifications. Colon tissues (50 mg) were washed, homogenized in cooled phosphate-buffered saline (PBS, $80 \mathrm{mM}$, pH 5.4) containing $0.5 \%$ hexadecyltrimethylammonium bromide (HTAB) and centrifuged at $12,000 \mathrm{x} \mathrm{g}$, for $20 \mathrm{~min}$ at $4^{\circ} \mathrm{C}$. The supernatant was added to a mixture of $150 \mu 13,3$,5,5 -tetramethylbenzidine (2 mM), $50 \mu \mathrm{l} \mathrm{H}_{2} \mathrm{O}_{2}(300 \mathrm{mM}), 250 \mu \mathrm{l} \mathrm{PBS}$ (pH 5.4, $80 \mathrm{mM}$ ) and incubated for $30 \mathrm{~min}$ at $25^{\circ} \mathrm{C}$. The reaction was quenched by $2.5 \mathrm{ml} \mathrm{H}_{2} \mathrm{SO}_{4}(200 \mathrm{mM})$ and the absorbance of the resulting mixture was measured at $450 \mathrm{~nm}$ with a UV-2401PC spectrophotometer (Shimadzu Corporation, Kyoto, Japan).

Lipid peroxidation levels. Lipid peroxidation was measured by the thiobarbituric acid (TBA)-reactive substance (TBARS) assays for malondialdehyde (MDA) following a previously described method (22), but with modifications. Colon tissue (100 mg) was washed and homogenized in cooled PBS. Total protein was determined with a bicinchoninic acid (BCA) assay. The suspension was mixed with $1 \mathrm{ml}$ TBA $(0.67 \%$, w/v) and $1 \mathrm{ml}$ trichloroacetic acid (TCA; 25\%, w/v), heated for $45 \mathrm{~min}$ at $95^{\circ} \mathrm{C}$ and centrifuged at $12,000 \mathrm{x} \mathrm{g}$ for $20 \mathrm{~min}$ at $4^{\circ} \mathrm{C}$. TBA reacted with the oxidative degradation products of lipids, yielding red complexes that are absorbed at $535 \mathrm{~nm}$. The volume of MDA was determined using a spectrophotometer (UV-2401PC).

Glutathione (GSH) levels. GSH levels were assessed as described previously by Ellman (23). Colon tissue (100 mg) was washed and homogenized in cooled PBS. The homogenate $(0.5 \mathrm{ml})$ was well mixed with $10 \%$ TCA $(0.5 \mathrm{ml})$ and centrifuged at $3,000 \mathrm{x} \mathrm{g}$ for $5 \mathrm{~min}$. An aliquot of supernatant $(0.1 \mathrm{ml})$ was mixed with $1.7 \mathrm{ml}$ of potassium phosphate buffer (0.1 M, pH 8.0) and $0.1 \mathrm{ml}$ of Ellman's reagent. After $5 \mathrm{~min}$, the optical density was measured at $412 \mathrm{~nm}$ against a blank using a spectrophotometer (UV-2401PC).

Measurement of colonic pro-inflammation cytokine levels. Colon samples were washed and homogenized for $5 \mathrm{~min}$ in $3 \mathrm{ml}$ PBS (0.1 M, pH 7.4) at $4^{\circ} \mathrm{C}$. The tissue homogenates were centrifuged at $12,000 \times \mathrm{g}$ for $5 \mathrm{~min}$ at $4^{\circ} \mathrm{C}$. Colonic levels of TNF- $\alpha$, IL-1 $\beta$ and -6 were measured with a commercial enzyme-linked immunosorbent assay kit (ELISA MAX, BioLegend Inc., San Diego, CA, USA) according to the manufacturer's instructions.

$R T-P C R$ assay. mRNA expression of TNF- $\alpha$, IL-1 $\beta,-6$, inducible nitric oxide synthase (iNOS) and cyclooxygenase-2 (COX-2) in the colon tissue, was measured with RT-PCR. Total RNA was isolated with TRIzol reagent and centrifuged at $12,000 \mathrm{x} \mathrm{g}$, for $15 \mathrm{~min}$ at $25^{\circ} \mathrm{C}$, following the addition of chloroform. Isopropanol was added to the supernatant at a $1: 1$ ratio and the RNA was pelleted by centrifugation at $12,000 \mathrm{x} g$ for $15 \mathrm{~min}$. After washing with ethanol, the RNA was solubilized in diethyl pyrocarbonate-treated RNase-free water and quantified by measuring the absorbance at $260 \mathrm{~nm}$ using a spectrophotometer (UV-2401PC). Equal amounts of RNA $(1 \mu \mathrm{g})$ were reverse transcribed in a master mix containing $1 \mathrm{X}$ reverse transcriptase buffer, $1 \mathrm{mM}$ dNTPs, $500 \mathrm{ng}$ of oligodT $_{18}$ primers, 140 units of MMLV reverse transcriptase and 40 units of RNase inhibitor for $45 \mathrm{~min}$ at $42^{\circ} \mathrm{C}$. PCR was then carried out in an automatic thermocycler 
Table I. Effects of kudingcha methanol extract on the levels of malondialdehyde and glutathione in the colon tissue of dextran sulfate sodium-treated mice.

Groups

Normal control

DSS

DSS + KME $(50 \mathrm{mg} / \mathrm{kg})$

DSS + KME $(200 \mathrm{mg} / \mathrm{kg})$
GSH

( $\mu \mathrm{mol} / \mathrm{mg}$ protein)

MDA

(nmol/mg protein)
$0.47 \pm 0.02^{\mathrm{d}}$

$0.98 \pm 0.10^{\mathrm{a}}$

$0.79 \pm 0.07^{\mathrm{b}}$

$0.63 \pm 0.07^{\mathrm{c}}$

Data are represented as the mean \pm standard deviation. ${ }^{\mathrm{a}-\mathrm{d}}$ Different letters are significantly different $(\mathrm{P}<0.05)$ by Duncan's multiple range tests MDA, malondialdehyde; GSH, glutathione; DSS, dextran sulfate sodium, KME, kudingcha methanol extract.

(Bioneer, Daejeon, South Korea) for 25 cycles $\left(94^{\circ} \mathrm{C}\right.$ for $30 \mathrm{sec}, 55^{\circ} \mathrm{C}$ for $30 \mathrm{sec}$ and $72^{\circ} \mathrm{C}$ for $\left.40 \mathrm{sec}\right)$ followed by an 8 min extension at $72^{\circ} \mathrm{C}$. The PCR products were separated in $2 \%$ agarose gels and visualized by $\mathrm{EtBr}$ staining. $\beta$-actin was used for normalization.

Statistical analysis. Data were presented as the mean \pm standard deviation. Differences between the mean values for individual groups were assessed by a one-way analysis of variance with Duncan's multiple range tests. $\mathrm{P}<0.05$ was considered to indicate a statistically significant difference. The SAS v9.1 statistical software package (SAS Institute Inc., Cary, NC, USA) was used for analysis.

\section{Results}

KME attenuated DSS-induced colitis symptoms. No animals died during the experimental period. As shown in Fig. 1A, the body weight gain of mice in the DSS group was significantly lower than that in the normal control group. KME-treated groups prevented the DSS-induced body weight loss. The symptoms of DSS-induced colitis in mice were similar to those observed in humans, such as body weight loss, diarrhea and gross bleeding (24). We quantitatively scored these symptoms according to the DAI. The DAI score indicated that KME alleviated the severity of DSS-induced colitis (Fig. 1C). DSS-induced colitis is associated with a marked decrease in colon length (25). As shown in Fig. 1B, DSS significantly decreased the colon length in the DSS treatment group $(5.7 \pm 0.5 \mathrm{~cm})$, compared with that in the normal control group $(9.0 \pm 0.4 \mathrm{~cm})$. However, KME was able to reduce the DSS-induced colon shortening in mice with colitis. In addition, colon weight to length ratio was used as an indicator of disease-associated intestinal wall thickening and intensity of inflammation. KME significantly inhibited DSS-induced intestinal wall thickening compared with that of the normal control group (Fig. 1D).

Effects of KME on histological changes and MPO activity in DSS-induced colitis mice. The H\&E staining assay was used to evaluate the therapeutic effects of KME in DSS-induced colonic inflammation and mucosal injury in colitis mice. As is evident in Fig. 2A, the tissue sections from normal mice showed intact surface epithelium, cryptal gland, stroma and submucosa, while the tissue sections from the DSS-induced colitis mice showed distorted crypt epithelium and extensive mucosal damage with a large number of inflammatory cells (Fig. 2B). However, tissue sections from KME-treated DSS-colitis mice had more intact surface epithelium, crypt glands and less inflammatory reactions than those in the DSS-colitis mice (Fig. 2C and D).

MPO activity, which is an indicator of acute inflammation, reflects the volume of neutrophil infiltration (26). DSS significantly increased the colonic MPO activity in colitis mice. However, following a treatment of 50 and $200 \mathrm{mg} / \mathrm{kg} \mathrm{KME}$ significantly suppressed MPO accumulation in the colonic tissues of DSS-induced colitis mice (Fig. 2E).

Effects of KME on GSH and MDA levels in DSS-induced colitis mice. DSS significantly increased the colonic MDA levels (to $0.98 \pm 0.10 \mathrm{nmol} / \mathrm{mg}$ protein) compared with that of the normal control group $(0.47 \pm 0.02 \mathrm{nmol} / \mathrm{mg}$ protein) (Table I). KME significantly reduced the colonic MDA levels of $0.79 \pm 0.07$ and $0.63 \pm 0.07 \mathrm{nmol} / \mathrm{mg}$ protein at 50 and $200 \mathrm{mg} / \mathrm{kg} \mathrm{KME}$, respectively. In addition, KME also attenuated the DSS-induced reduction in colonic GSH levels in the colitis mice. The colonic GSH levels of the DSS-colitis mice significantly increased following treatment with $\mathrm{KME}$, with the increased levels ranging from $4.58 \pm 0.44$ to $5.84 \pm 0.49 \mu \mathrm{mol} / \mathrm{mg}$ protein at 50 and $200 \mathrm{mg} / \mathrm{kg} \mathrm{KME}$, respectively.

Effects of KME on the colonic and mRNA levels of pro-inflammatory cytokines in DSS-induced colitis mice. Increased pro-inflammatory cytokine levels are associated with the UC pathological process. As shown in Fig. 3A, DSS significantly increased the colonic levels of TNF- $\alpha$, IL- $1 \beta$ and -6 . KME significantly reduced the levels of TNF- $\alpha$, IL-1 $\beta$ and -6 compared with that in the DSS-induced mice with colitis. To investigate the anti-inflammatory effects of KME on DSS-induced colitis in mice, mRNA expression of TNF- $\alpha$, IL-1 $\beta$ and -6 in colonic tissue was analyzed by RT-PCR. As shown in Fig. 3B, colonic inflammation induced by DSS. resulted in an elevated expression of all pro-inflammatory cytokines. Our findings demonstrate that administration of KME effectively reduced the mRNA expression of TNF- $\alpha$, IL-1 $\beta$ and -6 in the colon tissue of mice with DSS-induced colitis. 

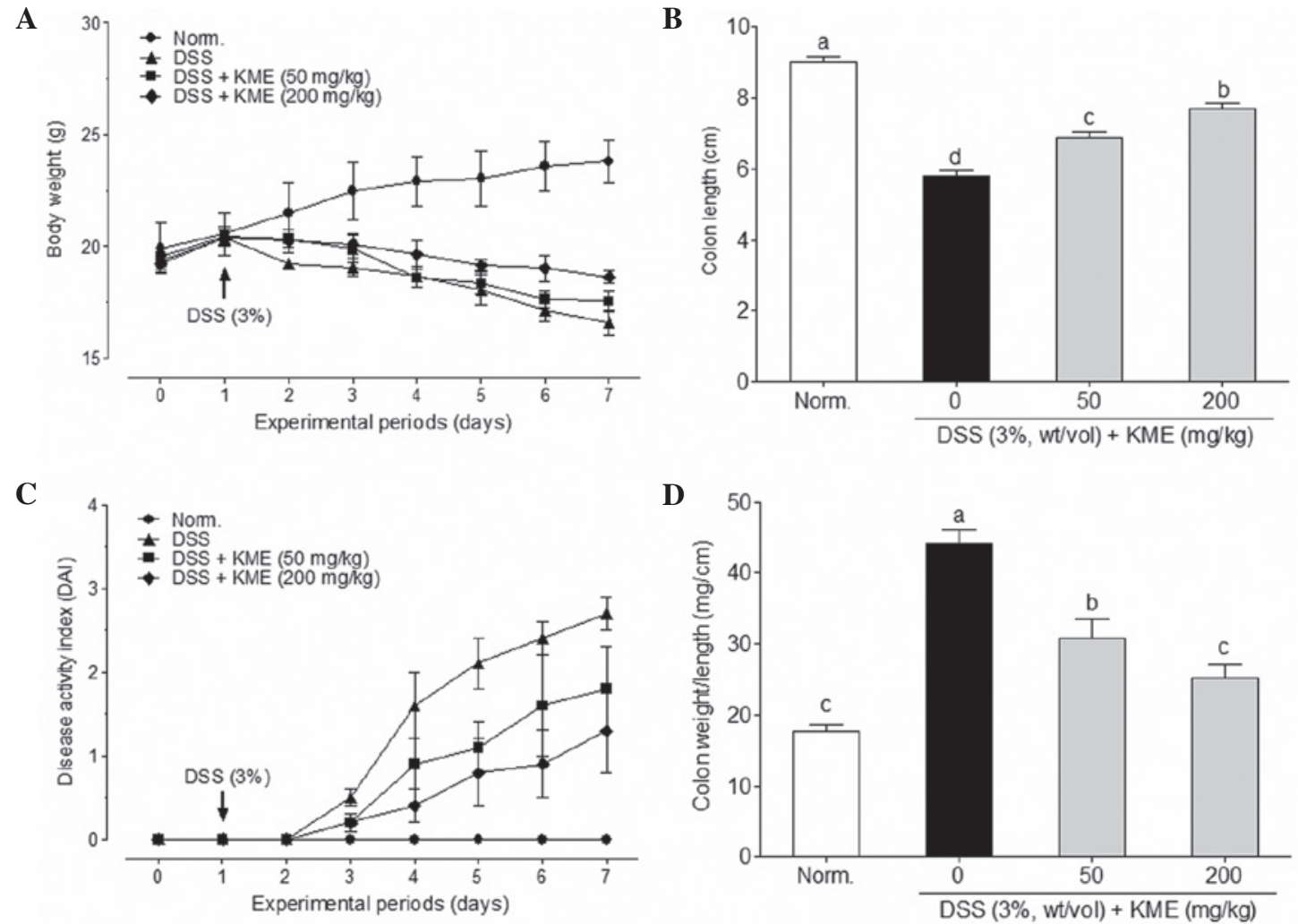

Figure 1. Effects of kudingcha methanol extract (KME) on (A) body weight changes (B) colon length; (C) disease activity index (DAI) and (D) colon weight to

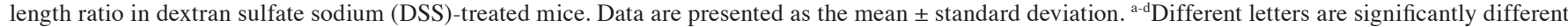
$(\mathrm{P}<0.05)$ by Duncan's multiple range tests.

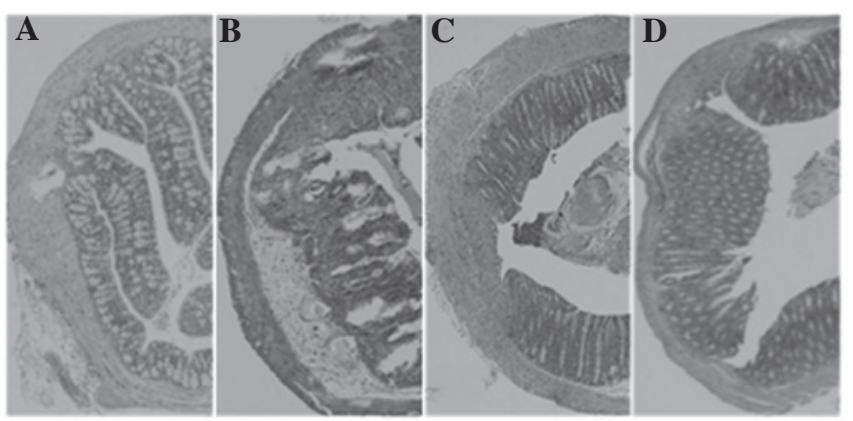

$\mathbf{E}$

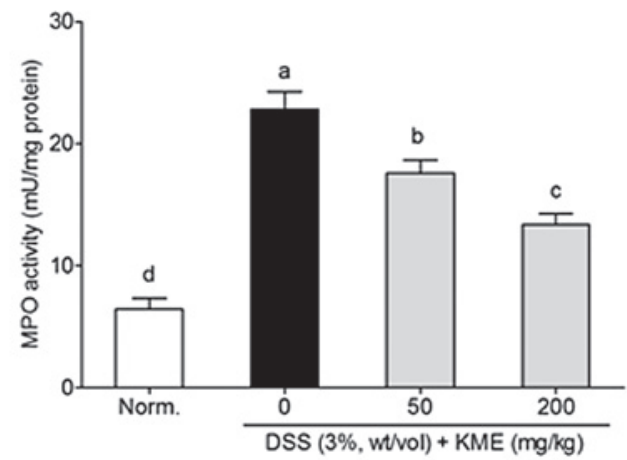

Figure 2. Effects of kudingcha methanol extract (KME) on colonic histological observations and myeloperoxidase (MPO) activity in dextran sulfate sodium (DSS)-treated mice. (A) Normal control group received water; (B) mice exposed to 3\% DSS in vehicle; (C and D) co-treatment with 50 and $200 \mathrm{mg} / \mathrm{kg} \mathrm{KME}$, respectively, for 7 days together with DSS administration (magnification for A-D, x40); (E) MPO activity was assayed according to criteria defined in Materials and methods. Data are presented as the mean \pm standard deviation. ${ }^{\mathrm{a}-\mathrm{d}}$ Different letters are significantly different $(\mathrm{P}<0.05)$ by Duncan's multiple range tests.

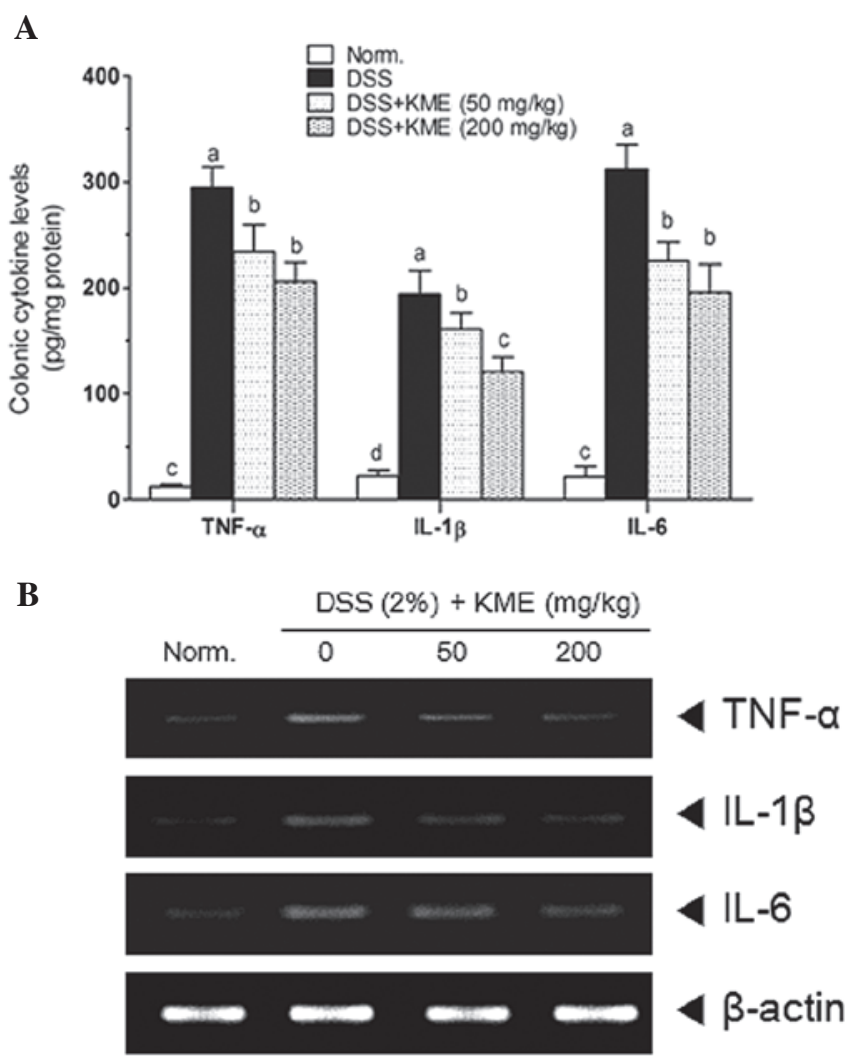

Figure 3. Effects of kudingcha methanol extract (KME) on colonic (A) and mRNA (B) levels of TNF- $\alpha$, IL-1 $\beta$ and -6 in dextran sulfate sodium (DSS)-treated mice. Data are presented as the mean \pm standard deviation. ${ }^{\mathrm{a}-\mathrm{d}}$ Different letters are significantly different $(\mathrm{P}<0.05)$ by Duncan's multiple range tests. 


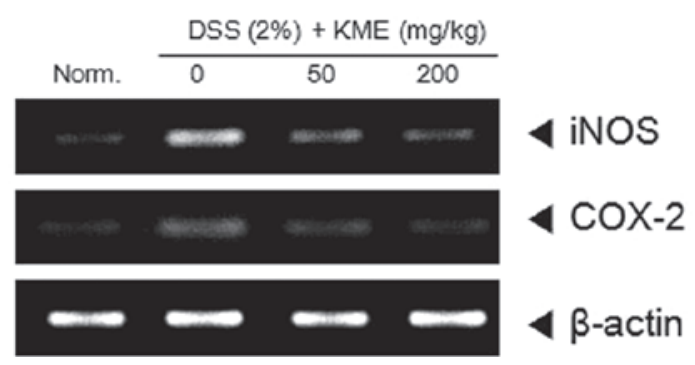

Figure 4. Effects of kudingcha methanol extract (KME) on the mRNA levels of inducible nitric oxide synthase (iNOS) and cyclooxygenase-2 (COX-2) in the colon tissue of dextran sulfate sodium (DSS)-treated mice.

KME inhibited the iNOS and COX-2 gene expression in DSS-induced colitis mice. iNOS and COX-2 are two types of inflammation-related enzymes and are important in the pathological process of UC. Therefore, we evaluated the effects of KME on iNOS and COX-2 mRNA expression in the colonic tissue of DSS-colitis mice compared with that of the untreated DSS-colitis mice. As shown in Fig. 4, DSS significantly increased the mRNA levels of iNOS and COX-2 in the colonic tissue of DSS-induced colitis mice. In addition, KME significantly and dose-dependently reduced the iNOS and COX-2 mRNA levels.

\section{Discussion}

In western countries, the incidence and prevalence of IBD has increased in the past 50 years from 8-14/100,000 to $120-200 / 100,000$ in individuals with UC (27). Recently, the prevalence of $\mathrm{UC}$ has been on the increase in the Asian-Pacific region (28). In general, therapeutic treatment for UC includes anti-inflammation and immunosuppression. However, these treatments have also been associated with undesirable side effects. Therefore, natural medicine has become an alternative therapy in addition to the conventional therapies that are used to treat UC (29). In the present study, we investigated the anti-inflammatory activity of kudingcha methanol extracts (KME) using DSS-induced mice colitis model. KME (50 and $200 \mathrm{mg} / \mathrm{kg}$ ) and DSS (3\%) in mice were orally coadministered and then clinical colitis was assessed by examining body weight loss, shortening of the colon length, increasing colon weight to length ratio and the DAI.

KME administration attenuated body weight loss, colonic shortening and intestinal wall thickening that was induced by DSS (Fig. 1). DSS significantly induced inflammatory cell infiltration, mucosal erosion, distortion and loss of crypts (Fig. 2B), as well as elevated MPO accumulation in the colon tissue of DSS-colitis mice (Fig. 2E). MPO, a member of the hemeperoxidase-cyclooxygenase superfamily, is abundantly expressed in neutrophils, and to a lesser extent in monocytes and certain types of macrophages (31). It is a specific marker that may be used to determine neutrophil influx into the colon tissue. The decrease in MPO activity may be explained through the reduction of neutrophil accumulation in inflamed tissues (32). In the present study, KME markedly reduced leukocyte (neutrophil and macrophage) infiltration and also decreased the colonic MPO levels to ameliorate the inflammatory conditions in the colonic tissues of DSS-induced colitis mice.
A typical development of DSS-induced colitis is leukocyte infiltration into the colonic tissues. Leukocyte infiltration is an important source of reactive oxygen species (ROS) and reactive nitrogen species (RNS), which act as cytotoxic agents by cross-linking proteins, lipids and nucleic acids, thus causing cell damage (33). Excess ROS markedly disrupts the oxidant/antioxidant balance as shown by the increased lipid peroxidation and reduction in colonic GSH content $(34,35)$. Oxidative stress or cellular damage with its dual of free radicals, generates profound lipid peroxidation and are the hallmarks of UC (36). As a good in vitro free radical scavenger $(12,19)$, KME markedly increased the colonic GSH levels and reduced the generation of MDA to attenuate the DSS-induced colitis in mice.

It is well known that the increased pro-inflammatory cytokines (TNF- $\alpha$, IL-1 $\beta$ and - 6 ) amplify the inflammatory cascade and result in intestinal tissue damage in patients with $\mathrm{UC}$, as well as in animal models of DSS-induced colitis $(5,37,38)$. The downregulation and/or blockade of pro-inflammatory cytokine activity was useful in the treatment of IBD (39). For example, anti-TNF- $\alpha$ antibody (Infilximab, a mouse monoclonal antibody) had effective therapeutic effects on UC in a clinical case $(40,41)$. In addition, IL-1 $\beta$ and -6 are two key mediators of the progression of UC. IL- $1 \beta$ is known to stimulate diarrhea and the reduction of its function subsequently suppressed the infiltration of inflammatory cells into the intestinal tissue and inhibited intestinal necrosis in animals with UC (42-44). Furthermore, anti-IL-1 $\beta$ antibody attenuated not only the symptoms of DSS-induced colitis, but also IL-6 gene expression (45). In the present study, we observed that the colonic levels of TNF- $\alpha$, IL-1 $\beta$ and -6 in the DSS-induced colitis mice were markedly decreased by KME administration, as identified by ELISA (Fig. 3A). The RT-PCR assay also confirmed that the mRNA levels of these pro-inflammatory cytokines were reduced by KME in the colonic tissue of DSS-induced colitis mice (Fig. 3B). These results indicate that KME may exert anti-inflammatory effects on DSS-induced colitis by reducing the activity of TNF- $\alpha$, IL- $1 \beta$ and -6 .

Previous studies have indicated that iNOS and COX-2 are considered to be vital in the inflammatory process of UC $(5,46,47)$. Pro-inflammatory cytokines induced the mRNA expression of iNOS and increased the generation of nitric oxide (NO), which is an inflammatory mediator associated with the pathological process of UC. Suppression of iNOS attenuated UC in human and animal cases $(47,48)$. Moreover, the inhibition of excessive COX-2 activity induced the generation of prostaglandins E2 (PGE2), which may result in the suppression of DSS-induced colitis in mice $(49,50)$. In the present study, we demonstrated that KME decreased the mRNA expression of iNOS and COX-2 in the colonic tissue of DSS-induced colitis mice (Fig. 4).

In conclusion, results of the present study have demonstrated the potential anti-inflammatory effects of KME in DSS-induced colitis mice. These results suggest that KME administration prevents DSS-induced body weight loss, colonic shortening and modulates MPO activity, as well as reducing intestinal wall thickening. In addition, KME administration increased the colonic GSH levels, decreased colonic lipid peroxidation, and reduced the production and mRNA levels of TNF- $\alpha$, IL- $1 \beta$ and -6 . Results of the present study suggest 
that the potential mechanism of KME involves suppressing the production of TNF- $\alpha$, IL-1 $\beta,-6$, iNOS and COX-2, and may be considered an important anti-inflammatory treatment agent against colonic inflammation.

\section{References}

1. Macdonald TT and Monteleone G: Immunity, inflammation, and allergy in the gut. Science 307: 1920-1925, 2005.

2. Bouma $\mathrm{G}$ and Strober W: The immunological and genetic basis of inflammatory bowel disease. Nat Rev Immunol 3: 521-533, 2003.

3. Ardizzone S and Bianchi Porro G: Biologic therapy for inflammatory bowel disease. Drugs 65: 2253-2286, 2005.

4. Hanauer SB: Inflammatory bowel disease: epidemiology, pathogenesis, and therapeutic opportunities. Inflamm Bowel Dis 12: S3-S9, 2006.

5. Podolsky DK: Inflammatory bowel disease. N Engl J Med 347: 417-429, 2002

6. Rogler G and Andus T: Cytokines in inflammatory bowel disease. World J Surg 22: 382-389, 1998.

7. van Dieren JM, Kuipers EJ, Samsom JN, Nieuwenhuis EE and van der Woude CJ: Revisiting the immunomodulators tacrolimus, methotrexate, and mycophenolate mofetil: their mechanisms of action and role in the treatment of IBD. Inflamm Bowel Dis 12: 311-327, 2006

8. Xu CT, Meng SY and Pan BR: Drug therapy for ulcerative colitis. World J Gastroenterol 10: 2311-2317, 2004.

9. Sun Y, Xu W, Zhang W, Hu Q and Zeng X: Optimizing the extraction of phenolic antioxidants from kudingcha made from Ilex kudingcha C.J. Tseng by using response surface methodology. Sep Sci Technol 78: 311-320, 2011

10. Nishimura K, Fukuda T, Miyase T, Noguchi H and Chen XM: Activity-guided isolation of triterpenoid acyl CoA cholesteryl acyl transferase (ACAT) inhibitors from Ilex kudincha. J Nat Prod 62: 1061-1064, 1999.

11. Zhu F, Cai YZ, Sun M, Ke J, Lu D and Corke H: Comparison of major phenolic constituents and in vitro antioxidant activity of diverse kudingcha genotypes from Ilex kudingcha, Ilex cornuta, and Ligustrum robustum. J Agric Food Chem 57: 6082-6089, 2009.

12. Thuong PT, Su ND, Ngoc TM, Hung TM, Dang NH, Thuan ND Bae $\mathrm{K}$ and Oh WK: Antioxidant activity and principles of Vietnam bitter tea Ilex kudingcha. Food Chem 113: 139-145, 2009.

13. Chen ZY, Wong IY, Leung MW, He ZD and Huang Y: Characterization of antioxidants present in bitter tea (Ligustrum pedunculare). J Agric Food Chem 50: 7530-7535, 2002.

14. Wong IY, He ZD, Huang Y and Chen ZY: Antioxidative activities of phenylethanoid glycosides from Ligustrum purpurascens. J Agric Food Chem 49: 3113-3119, 2001.

15. She GM, Wang D, Zeng SF, Yang CR and Zhang YJ: New phenylethanoid glycosides and sugar esters from ku-ding-cha a herbal tea produced from Ligustrum purpurascens. J Food Sci 73: C476-C481, 2008

16. Lau KM, He ZD, Dong H, Fung KP and But PP: Antioxidative, anti-inflammatory and hepato-protective effects of Ligustrum robustum. J Ethnopharmacol 83: 63-71, 2002.

17. Pu F, Mishima K, Irie K, Egashira N, Ishibashi D, Matsumoto Y, Ikeda T, Iwasaki K, Fujii $H$, Kosuna $K$ and Fujiwara $M$ : Differential effects of buckwheat and kudingcha extract on neuronal damage in cultured hippocampal neurons and spatial memory impairment induced by scopolamine in an eight-arm radial maze. J Health Sci 51: 636-644, 2005

18. Kim JY, Jeong HY, Lee HK, Yoo JK, Bae K and Seong YH: Protective effect of Ilex latifolia, a major component of 'kudingcha', against transient focal ischemia-induced neuronal damage in rats. J Ethnopharmacol 133: 558-564, 2011.

19. Liu L, Sun Y, Laura T, Liang X, Ye H and Zeng X: Determination of polyphenolic content and antioxidant activity of Kudingcha made from Ilex kudingcha C.J. Tseng. Food Chem 112: 35-41, 2009 .

20. Azuma YT, Nishiyama K, Matsuo Y, Kuwamura M, Morioka A, Nakajima $\mathrm{H}$ and Takeuchi T: PPAR $\alpha$ contributes to colonic protection in mice with DSS-induced colitis. Int Immunopharmacol 10: 1261-1267, 2010.
21. Shin VY, Liu ES, Koo MW, Wang JY, Matsui $\mathrm{H}$ and Cho $\mathrm{CH}$ : Cigarette smoke extracts delay wound healing in the stomach: involvement of polyamine synthesis. Exp Biol Med (Maywood) 227: 114-124, 2002.

22. Gan XL, Hei ZQ, Huang HQ, Chen LX, Li SR and Cai J: Effect of Astragalus membranaceus injection on the activity of the intestinal mucosal mast cells after hemorrhagic shock-reperfusion in rats. Chin Med J (Engl) 119: 1892-1898, 2006.

23. Ellman GL: Tissue sulfhydryl groups. Arch Biochem Biophys 82 70-77, 1959.

24. Strober W, Fuss IJ and Blumberg RS: The immunology of mucosal models of inflammation. Annu Rev Immunol 20: 495-549, 2002

25. Hendrickson BA, Gokhale R and Cho JH: Clinical aspects and pathophysiology of inflammatory bowel disease. Clin Microbiol Rev 15: 79-94, 2002.

26. Yamamki K, Kim DH, Ryu N, Kim YP, Shin KH and Ohuchi K: Effects of naturally occurring isoflavones on prostaglandin E2 production. Planta Med 68: 97-100, 2002

27. Cosnes J, Gower-Rousseau C, Seksik P and Cortot A: Epidemiology and natural history of inflammatory bowel diseases. Gastroenterology 140: 1785-1794, 2011.

28. Chung HL, Yue GG, To KF, Su YL, Huang Y and Ko WH: Effect of Scutellariae Radix extract on experimental dextransulfate sodium-induced colitis in rats. World J Gastroenterol 13: 5605-5611, 2007.

29. Langmead L, Dawson C, Hawkins C, Banna N, Loo S and Rampton DS: Antioxidant effects of herbal therapies used by patients with inflammatory bowel disease: an in vitro study. Aliment Pharmacol Ther 16: 197-205, 2002.

30. Malle E, Furtmüller P, Sattler W and Obinger C: Myeloperoxidase: a target for new drug development? Br J Pharmacol 152: 838-854, 2007.

31. Babbs CF: Oxygen radicals in ulcerative colitis. Free Radic Biol Med 13: 169-181, 1992.

32. Holma R, Salmenperä P, Riutta A, Virtanen I, Korpela R and Vapaatalo H: Acute effects of the cys-leukotriene-1 receptor antagonist, montelukast, on experimental colitis in rats. Eur J Pharmacol 429: 309-318, 2001

33. Mustafa A, EI-Medany A, Hagar HH and EI-Medany G: Ginkgo biloba attenuates mucosal damage in a rat model of ulcerative colitis. Pharmacol Res 53: 324-330, 2006.

34. Osman N, Adawi D, Ahrné S, Jeppsson B and Molin G: Probiotics and blueberry attenuate the severity of dextran sulfate sodium (DSS)-induced colitis. Dig Dis Sci 53: 2464-2473, 2008

35. Fiocchi C: Inflammatory bowel disease: new insights into mechanisms of inflammation and increasingly customized approaches to diagnosis and therapy. Curr Opin Gastroenterol 20: 309-310, 2004.

36. Dieleman LA, Palmen MJ, Akol H, Bloemena E, Peña AS Meuwissen SG and Van Rees EP: Chronic experimental colitis induced by dextran sulphate sodium (DSS) is characterized by Th1 and Th2 cytokines. Clin Exp Immunol 114: 385-391, 1998.

37. Bai A and Peng Z: Biological therapies of inflammatory bowel disease. Immunotherapy 2: 727-742, 2010.

38. Perrier C and Rutgeerts P: Cytokine blockade in inflammatory bowel diseases. Immunotherapy 3: 1341-1352, 2011.

39. Rutgeerts P, Sandborn WJ, Feagan BG, Reinisch W, Olson A Johanns J, Travers S, Rachmilewitz D, Hanauer SB and Lichtenstein GR, et al: Infliximab for induction and maintenance therapy for ulcerative colitis. N Engl J Med 353: 2462-2476, 2005.

40. Duca I, Ramírez de la Piscina P, Estrada S, Calderón R, Spicakova K, Urtasun L, Marra-López C, Zabaleta S, Bengoa R, Marcaide MA and García-Campos F: Steroid-refractory ulcerative colitis and associated primary sclerosing cholangitis treated with infliximab. World J Gastroenterol 19: 590-593, 2013.

41. Siegmund B, Lehr HA, Fantuzzi G and Dinarello CA: IL-1 beta-converting enzyme (caspase-1) in intestinal inflammation. Proc Natl Acad Sci USA 98: 13249-13254, 2001.

42. Tountas NA, Casini-Raggi V, Yang H, Di Giovine FS, Vecchi M, Kam L, Melani L, Pizarro TT, Rotter JI and Cominelli F: Functional and ethnic association of allele 2 of the interleukin-1 receptor antagonist gene in ulcerative colitis. Gastroenterology 117: 806-813, 1999.

43. Dionne S, D'Agata ID, Hiscott J, Vanounou T and Seidman EG: Colonic explant production of IL-1 and its receptor antagonist is imbalanced in inflammatory bowel disease (IBD). Clin Exp Immunol 112: 435-442, 1998 
44. Kwon KH, Murakami A, Hayashi R and Ohigashi $\mathrm{H}$ : Interleukin-1beta targets interleukin-6 in progressing dextran sulfate sodium-induced experimental colitis. Biochem Biophys Res Commun 337: 647-654, 2005.

45. Papadakis KA and Targan SR: Role of cytokines in the pathogenesis of inflammatory bowel disease. Annu Rev Med 51: 289-298, 2000.

46. Dudhgaonkar S, Tandan SK, Kumar D, Raviprakash V and Kataria M: Influence of simultaneous inhibition of cyclooxygenase- 2 and inducible nitric oxide synthase in experimental colitis in rats. Inflammopharmacology 15: 188-195, 2007.
47. Cross RK and Wilson KT: Nitric oxide in inflammatory bowel disease. Inflamm Bowel Dis 9: 179-189, 2003.

48. Martín A, Villegas I and Alarcón de la Lastra C: The COX-2 inhibitor, rofecoxib, ameliorates dextran sulphate sodium induced colitis in mice. Inflamm Res 54: 145-151, 2005.

49. Tanaka K, Suemasu S, Ishihara T, Tasaka Y, Arai Y and Mizushima T: Inhibition of both COX-1 and COX-2 and resulting decrease in the level of prostaglandins E2 is responsible for non-steroidal anti-inflammatory drug (NSAID)-dependent exacerbation of colitis. Eur J Pharmacol 603: 120-132, 2009. 